\title{
Effect of root canal filling materials on dimensions of cone-beam computed tomography images
}

\author{
Daniel Almeida DECURCIO', Mike Reis BUENO², Ana Helena Gonçalves de ALENCAR', Olavo César Lyra PORTO³,
} Bruno Correa AZEVEDO ${ }^{4}$, Carlos ESTRELA ${ }^{5}$

\author{
1- DDS, MSc, PhD Professor of Endodontics, Department of Oral Science, Federal University of Goiás, Goiânia, GO, Brazil. \\ 2- DDS, MSc, Professor of Oral Diagnosis, Department of Oral Diagnosis, University of Cuiabá, Cuiabá, MT, Brazil. \\ 3- DDS, MSc, Graduate student (Master's Degree), Department of Oral Sciences, Federal University of Goiás, Goiânia, GO, Brazil. \\ 4- DDS, MSc, Assistant Professor of Oral Maxillofacial Radiology, Western University, Pomona, CA, USA. \\ 5- DDS, MSc, PhD, Chairman and Professor of Endodontics, Department of Oral Science, Federal University of Goiás, Goiânia, GO, Brazil.
}

Corresponding address: Prof. Carlos Estrela - Universidade Federal de Goiás - Departamento de Ciências Estomatológicas - Praça Universitária s/n, Setor Universitário

74605-220 - Goiânia - GO - Brazil - E-mail address: estrela3@terra.com.br

Received: September 07, 2010 - Modification: July 31, 2011 - Accepted: August 02, 2011

\section{ABSTRACT}

\begin{abstract}
bjective: To evaluate the discrepancy of root canal filling (RCF) measurements obtained from original root specimens and cone-beam computed tomography (CBCT) images. Material and Methods: Seventy-two human maxillary anterior teeth were prepared up to an ISO \#50 K-File $1 \mathrm{~mm}$ short of the apical foramen. Thus, the teeth were randomly divided into 8 groups, according to the root canal filling material: Sealapex ${ }^{\circledR}$, Sealapex ${ }^{\circledR}+$ guttapercha points, Sealer $26^{\circledR}$, Sealer $26^{\circledR}+$ gutta-percha points, AH PlusTM, AH PlusTM+guttapercha points, Grossman Sealer, and Grossman Sealer+gutta-percha points. After root canal preparation and RCF, CBCT scans were acquired and the specimens were sectioned in axial, sagittal and coronal planes. The RCF measurements were obtained in different planes and thicknesses to determine the discrepancy between the original root specimens (using a digital caliper) and the CBCT images (using the scanner's proprietary software). One-way analysis of variance and Tukey tests were used for statistical analyses. The significance level was set at $\alpha=5 \%$. Results: Measurements of the different endodontic filling materials were $9 \%$ to $100 \%$ greater on the CBCT images than on the original root specimens. Greater RCF dimensions were found when only sealers were used, with statistically significant difference among the groups. Conclusions: RCF dimensions were greater on CBCT images than on the original root specimens, especially when only sealer was used.
\end{abstract}

Key words: Cone-beam computed tomography. Diagnostic imaging. Artifacts. Root canal filling materials.

\section{INTRODUCTION}

The advent of computed tomography (CT) has started a revolution of information in health studies and has contributed to planning, diagnosis, treatment, and prognosis analysis of several diseases ${ }^{11}$. Cone-beam computed tomography $(C B C T)$ is a recently developed technology 2,25 with potential for applications in different areas of research and clinical dentistry 5,20,29.

In Endodontics, images are routinely used before, during, and after root canal treatment. Conventional radiographic images provide a twodimensional (2D) rendition of a three-dimensional
(3D) structure, which may result in interpretation errors.

Periapical lesions of endodontic origin may be present but not visible on conventional 2D radiographs ${ }^{4,6-8}$. These lesions are visible more often on CBCT images, and new methods using $\mathrm{CBCT}$ scans to investigate apical periodontitis and root resorption have been developed ${ }^{6-8}$, as new imaging tools are now used in several endodontic research areas $^{9,22}$. However, CBCT images are affected by high atomic number materials. Artifacts can cause low image quality and poor image contrast leading to limited interpretation of the 3D volumes. There is a concern with artifacts and the search for beam 
hardening corrections have been the focus of several studies $3,10,12,14,16-19,21,26-28$.

According to Ketcham and Carlson ${ }^{19}$ (2001) beam hardening is the most frequently artifact found in CT scanning. Beam hardening causes the edges of an object to appear as cupping, streaks, dark bands, or flare artifacts, and is caused by preferential absorption of low-energy photons by absorbing materials with higher atomic numbers (e.g. metals). Katsumata, et al. ${ }^{16}$ (2006) related that the СВСТ image defects often appeared in images of solid non anatomical objects placed on the dental arch, such as diagnostic stents (guide splint) for the accurate positioning of dental implants and rectangular radiopaque reference markers for the assessment of periodontal disease. This was more frequent when radiopaque materials, such as hydroxyapatite containing resin and aluminum, were used.

It is essential to understand, however, that image artifacts are likely to occur because of the density of several materials used in root canal treatment. Alterations from true dimension of RCF may offer false interpretation on real dentin remnants. Thus, evaluating the dimension of endodontic materials on CBCT images may warn the clinicians about the potential risks of misdiagnosis. This study evaluated the discrepancy of RCF measurements obtained from original root specimens and CBCT images.

\section{MATERIAL AND METHODS}

\section{Tooth preparation}

Seventy-two human maxillary anterior teeth, extracted for different reasons, were obtained from the Dental Urgency Service of the Federal University of Goiás - School of Dentistry, Goiânia, GO, Brazil. This study was approved by the Ethics Committee of the Federal University of Goiás, Brazil. Preoperative radiographs of each tooth were taken to confirm the absence of calcified root canal, internal or external resorption, and the presence of a fully formed apex.

The teeth were removed from storage in $0.2 \%$ thymol solution and immersed in 5\% sodium hypochlorite (Fitofarma, Goiânia, GO, Brazil) for $30 \mathrm{~min}$ to remove external organic tissues. The crowns were removed to set the remaining tooth length to a standardized $13 \mathrm{~mm}$ from the root apex. After taking the initial radiographs, standard access cavities were prepared, and the cervical third of each root canal was enlarged using ISO \#50 up to \#90 Gates-Glidden drills (Dentsply/Maillefer, Ballaigues, Switzerland). Teeth were prepared up to an ISO\#50K-File (Dentsply/Maillefer) $1 \mathrm{~mm}$ short of the apical foramen. During instrumentation, the root canals were irrigated with $3 \mathrm{~mL}$ of $1 \%$ $\mathrm{NaOCl}$ (Fitofarma) at each change of files. Root canals were dried and filled with 17\% EDTA (pH
7.2) (Biodinâmica, Ibiporã, PR, Brazil) for 3 min to remove the smear layer. After that, the root canals were irrigated again with $3 \mathrm{~mL}$ of $1 \% \mathrm{NaOCl}$, and dried with paper points (Dentsply/Maillefer).

The teeth were randomly divided into 8 experimental groups with 9 specimens each, according to different sealers: Group 1 - Sealapex ${ }^{\circledR}$ (Sybron Endo, Glendora, CA, USA); Group 2 - Sealapex ${ }^{\circledR}+$ gutta-percha points (Dentsply/ Maillefer); Group 3 - Sealer 26 ${ }^{\circledR}$ (Dentsply Ind. e Com. Ltda., Petrópolis, RJ, Brazil); Group 4 - Sealer $26^{\circledR}+$ gutta-percha points; Group 5 - $\mathrm{AH}$ Plus $^{\mathrm{TM}}$ (Dentsply/Maillefer); Group 6 - $\mathrm{AH}$ Plus $^{\mathrm{TM}}+$ guttapercha points; Group 7 - Grossman Sealer (Endofill, Dentsply); Group 8 - Grossman Sealer+guttapercha points.

The chemical composition of sealers used are: Sealapex (calcium oxide, bismuth trioxide, zinc oxide, sub-micron silica, titanium dioxide, zinc stearate, tricalcium phosphate, and blend - ethyl toluene sulfonamide, polymethylenemethylsalicylate resin, isobutyl salicylate and a pigment); Sealer 26 (bismuth trioxide, calcium hydroxide, tetraminehexamethilene, titanium dioxide and bisphenol epoxy resin); AH Plus (paste A - epoxy resins, calcium tungstate, zirconium oxide, silica, iron oxide pigments, and paste $\mathrm{B}$ - amines, calcium tungstate, zirconium oxide, silica, silicone oil); Grossman Sealer (zinc oxide, hydrogenated resin, bismuth subcarbonate, barium sulfate, sodium borate, eugenol and almond oil).

After root canal preparation, groups 1, 3, 5, and 7 were filled with the corresponding sealers prepared according to the manufacturer's directions and taken using a Lentulo spiral. In groups 2, 4, 6, and 8 , teeth were filled with the corresponding sealer and gutta-percha points using the conventional lateral condensation technique. The teeth were wrapped in wet gauze and placed in an incubator at $37^{\circ} \mathrm{C}$ for $72 \mathrm{~h}$ to allow complete set of the root canal filling materials. The coronal and the apical portion of the teeth were rendered waterproof with a layer of cyanoacrylate adhesive (Super Bonder, Itapevi, SP, Brazil) to protect against the influence of the water on materials.

\section{CBCT image acquisition}

Teeth were positioned in the center of a bucket filled with water to simulate soft tissue and supported by a plastic platform, based on the model used in previous studies ${ }^{16,26,28}$. CBCT images were acquired with the first generation i-CAT Cone Beam 3D imaging system (Imaging Sciences International, Hatfield, PA, USA). The volumes were reconstructed with $0.2 \mathrm{~mm}$ isometric voxel. The tube voltage was $120 \mathrm{kVp}$ and the tube current 3.8 $\mathrm{mA}$. Exposure time was $40 \mathrm{~s}$. 
Sectioning of roots

After obtaining the CBCT scans, the roots of all teeth were carefully sectioned in axial, sagittal or coronal planes using a high-speed Endo Z bur (Dentsply/Maillefer) under water spray cooling. The axial cuts were obtained at $6.5 \mathrm{~mm}$ from the root apex; and for sagittal and coronal planes, the roots were sectioned longitudinally, in the center of the root canal (Figure 1).
Measurement of specimens and CBCT slices

All measurements of the sectioned roots were made by two endodontists using a digital caliper accurate to $0.01 \mathrm{~mm}$ (Fowler/Sylvac Ultra-cal Mark IV Electronic Caliper, Crissier, Switzerland). The calibrated examiners measured all the specimens and CBCT images, and assessed RCF dimensions in the directions described below. When a consensus was not reached a third observer made the final

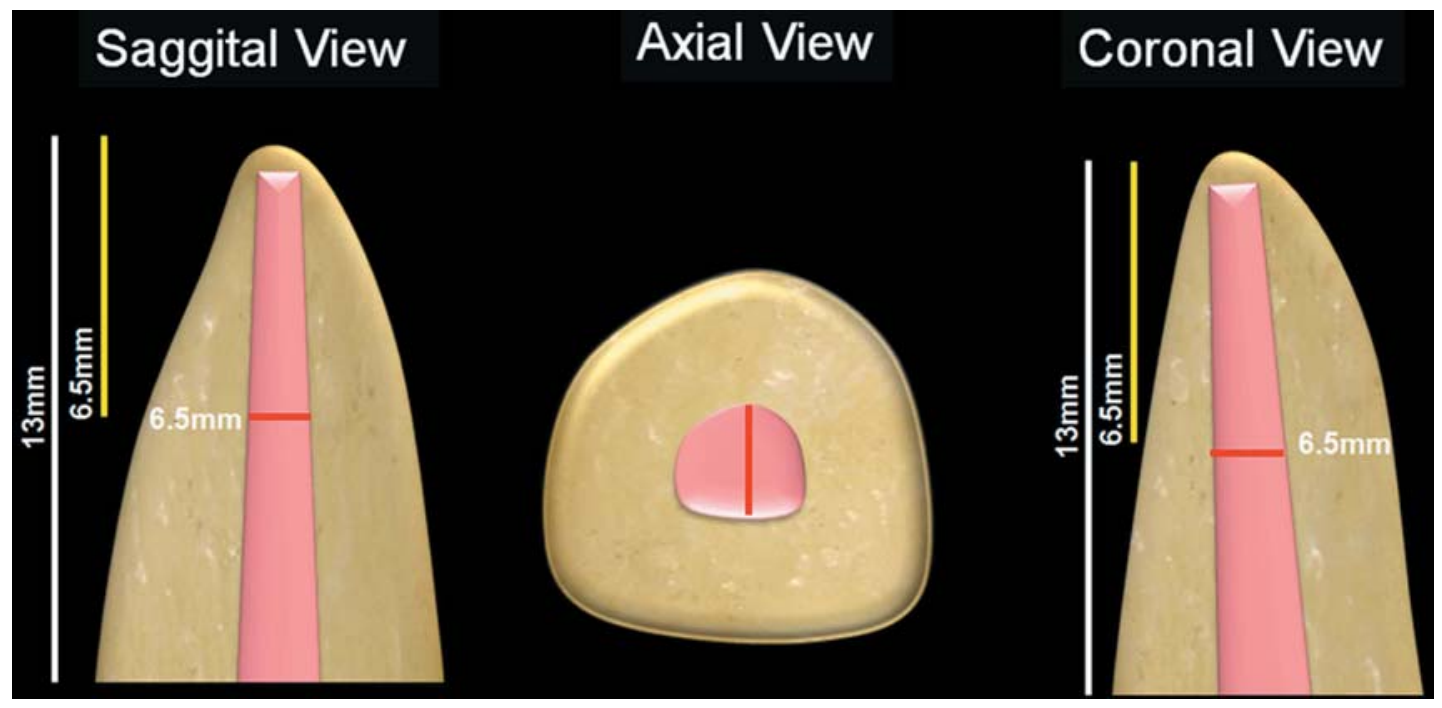

Figure 1- Schematic representation of sectioning root method and post length, showing the sagittal, axial, and coronal views

Table 1- Percentage (\%) of root canal filling dimension increase from original specimens to cone-beam computed tomography images according to slice thickness and planes for each endodontic material $(\alpha=5 \%)$

\begin{tabular}{|c|c|c|c|c|c|c|c|c|}
\hline $\begin{array}{c}\text { Materials/ } \\
\text { Thickness/ } \\
\text { Plane }\end{array}$ & AH Plus & $\begin{array}{c}\text { AH Plus + } \\
\text { GPP }\end{array}$ & Sealapex & $\begin{array}{c}\text { Sealapex + } \\
\text { GPP }\end{array}$ & $\begin{array}{c}\text { Grossman } \\
\text { Sealer }\end{array}$ & $\begin{array}{c}\text { Grossman } \\
\text { Sealer + } \\
\text { GPP }\end{array}$ & Sealer 26 & $\begin{array}{c}\text { Sealer } 26+ \\
\text { GPP }\end{array}$ \\
\hline $0.2 \mathrm{~mm} /$ Axial & 81.8 & 59.79 & 50.0 & 49.70 & 63.6 & 47.40 & 33.3 & 29.73 \\
\hline $0.2 \mathrm{~mm} /$ Coronal & 80.0 & 60.61 & 42.9 & 50.37 & 83.3 & 37.37 & 60.0 & 42.93 \\
\hline $0.2 \mathrm{~mm} /$ Sagittal & 40.0 & 33.33 & 60.0 & 41.41 & 60.0 & 40.10 & 27.3 & 29.06 \\
\hline $0.6 \mathrm{~mm} /$ Axial & 81.8 & 59.79 & 50.0 & 49.70 & 63.6 & 47.40 & 33.3 & 29.73 \\
\hline $0.6 \mathrm{~mm} /$ Coronal & 80.0 & 60.61 & 42.9 & 50.37 & 83.3 & 37.37 & 60.0 & 37.37 \\
\hline $0.6 \mathrm{~mm} /$ Sagittal & 40.0 & 33.33 & 60.0 & 29.80 & 60.0 & 40.10 & 27.3 & 29.06 \\
\hline $1 \mathrm{~mm} /$ Axial & 81.8 & 59.79 & 50.0 & 49.70 & 63.6 & 47.40 & 33.3 & 29.73 \\
\hline $1 \mathrm{~mm} /$ Coronal & 80.0 & 60.61 & 42.9 & 50.37 & 83.3 & 36.87 & 60.0 & 37.37 \\
\hline $1 \mathrm{~mm} /$ Sagittal & 40.0 & 33.33 & 60.0 & 24.24 & 60.0 & 40.10 & 27.3 & 23.93 \\
\hline $3 \mathrm{~mm} /$ Axial & 100.0 & 59.79 & 50.0 & 49.70 & 81.8 & 47.40 & 33.3 & 35.28 \\
\hline $3 \mathrm{~mm} /$ Coronal & 80.0 & 55.05 & 28.6 & 42.96 & 83.3 & 31.31 & 40.0 & 31.82 \\
\hline $3 \mathrm{~mm} /$ Sagittal & 40.0 & 27.27 & 60.0 & 18.18 & 40.0 & 34.04 & 9.1 & 18.80 \\
\hline $5 \mathrm{~mm} /$ Axial & 100.0 & 59.79 & 66.7 & 43.64 & 100.0 & 47.40 & 50.0 & 51.66 \\
\hline $5 \mathrm{~mm} /$ Coronal & 80.0 & 43.43 & 28.6 & 36.30 & 83.3 & 31.31 & 40.0 & 31.82 \\
\hline $5 \mathrm{~mm} /$ Sagittal & 40.0 & 15.15 & 40.0 & 18.18 & 40.0 & 27.98 & 9.1 & 18.80 \\
\hline$p$ value & $0.001^{*}$ & $0.014^{*}$ & $0.001^{*}$ & 0.760 & $0.001^{*}$ & 0.879 & $0.001^{*}$ & 0.392 \\
\hline
\end{tabular}

*interaction between type of cut and slice thickness significantly by Tukey test. GPP - Gutta-percha points 
Table 2- Percentage (\%) of root canal filling dimension increase from original specimens to cone-beam computed tomography images for each group according to sealers, slice thickness and planes, and statistical analysis $(\alpha=5 \%)$

\begin{tabular}{|c|c|c|c|c|c|c|c|c|}
\hline FACTOR & & & & & ROUPS & & & \\
\hline \multirow[t]{2}{*}{ Materials* } & $\begin{array}{c}\text { Grossman } \\
\text { Sealer }\end{array}$ & AH Plus & Sealapex & $\begin{array}{l}\text { AH Plus } \\
+ \text { GPP }\end{array}$ & $\begin{array}{l}\text { Sealapex } \\
\text { + GPP }\end{array}$ & $\begin{array}{c}\text { Grossman } \\
\text { Sealer + GPP }\end{array}$ & Sealer 26 & $\begin{array}{c}\text { Sealer } 26 \\
\text { + GPP }\end{array}$ \\
\hline & $69.94^{\mathrm{A}}$ & $69.69^{A}$ & $48.84^{\mathrm{BC}}$ & $48.12 \mathrm{~B}^{\mathrm{CD}}$ & $40.31^{\mathrm{BCDE}}$ & $39.57^{\mathrm{CDE}}$ & $36.22^{\mathrm{DE}}$ & $31.82^{\mathrm{E}}$ \\
\hline \multirow[t]{2}{*}{ Thickness ${ }^{* *}$} & $0.2 \mathrm{~mm}$ & & $0.6 \mathrm{~mm}$ & & $1 \mathrm{~mm}$ & & $3 \mathrm{~mm}$ & $5 \mathrm{~mm}$ \\
\hline & $50.53^{A}$ & & $49.89^{A}$ & & $49.48^{A}$ & & $46.70^{\mathrm{A}}$ & $46.16^{A}$ \\
\hline \multirow[t]{2}{*}{ Planes ${ }^{* * *}$} & \multirow{2}{*}{\multicolumn{3}{|c|}{$\begin{array}{l}\text { Axial } \\
59.28^{\mathrm{A}}\end{array}$}} & & Coronal & & \multirow{2}{*}{\multicolumn{2}{|c|}{$\begin{array}{l}\text { Sagittal } \\
35.48^{\mathrm{C}}\end{array}$}} \\
\hline & & & & & $50.89^{B}$ & & & \\
\hline
\end{tabular}

${ }^{*}$ Different letters in horizontal demonstrate statistically significant difference with $p<0.05$.

${ }^{*} p=0.0001$ by ANOVA test and $p=0.0001$ by Tukey test;

${ }^{* *} p=0.647$ by ANOVA test and $p=0.272$ by Tukey test;

${ }^{* * *} p=0.0001$ by ANOVA test and $p=0.0001$ by Tukey test.

GPP - Gutta-percha points.
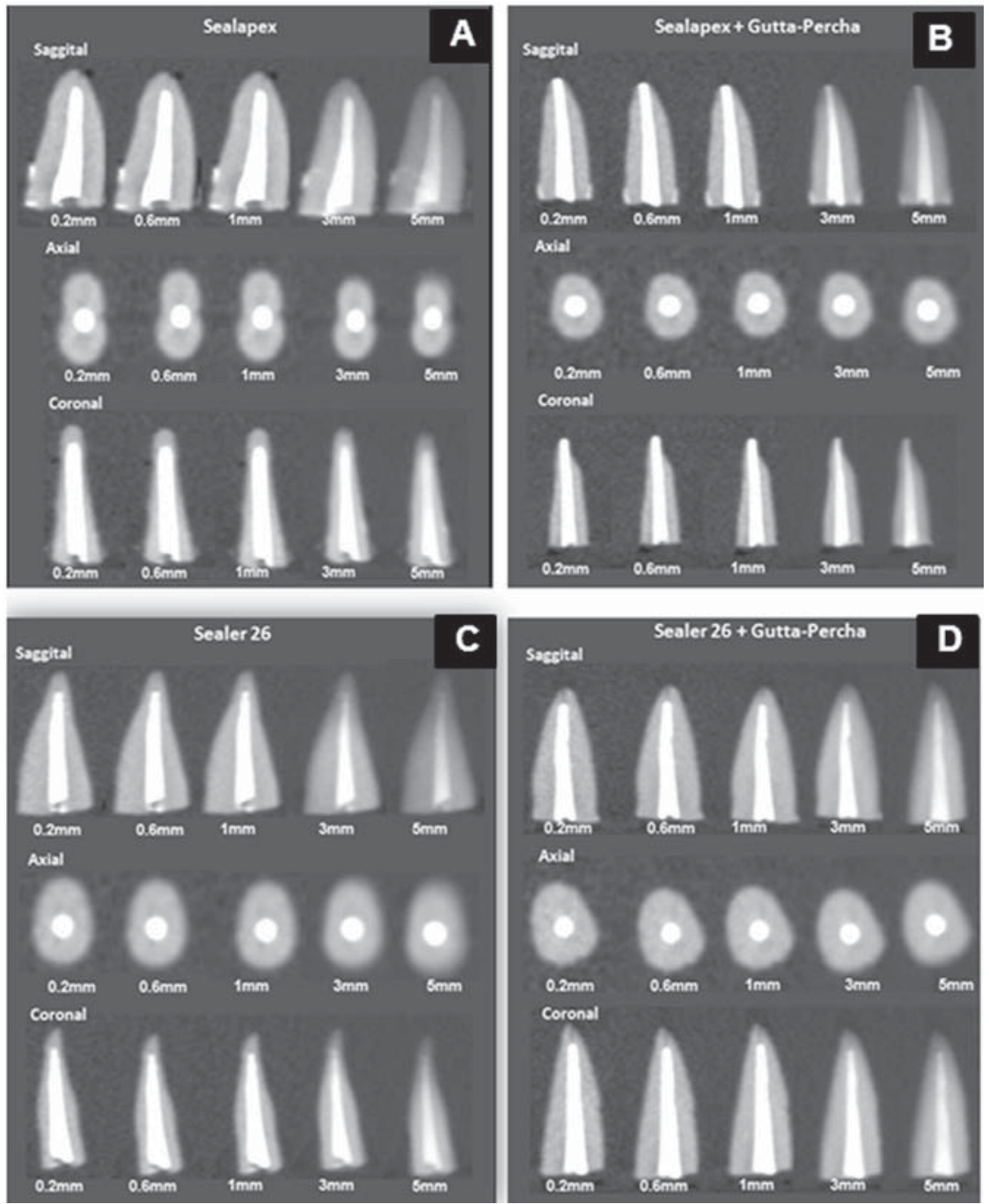

Figure 2- Cone-beam computed tomography images of root canal filling with Sealapex (A), Sealapex+gutta-percha (B), Sealer $26(C)$, and Sealer 26+gutta-percha (D) in different slice thickness and planes (sagittal, axial and coronal) 

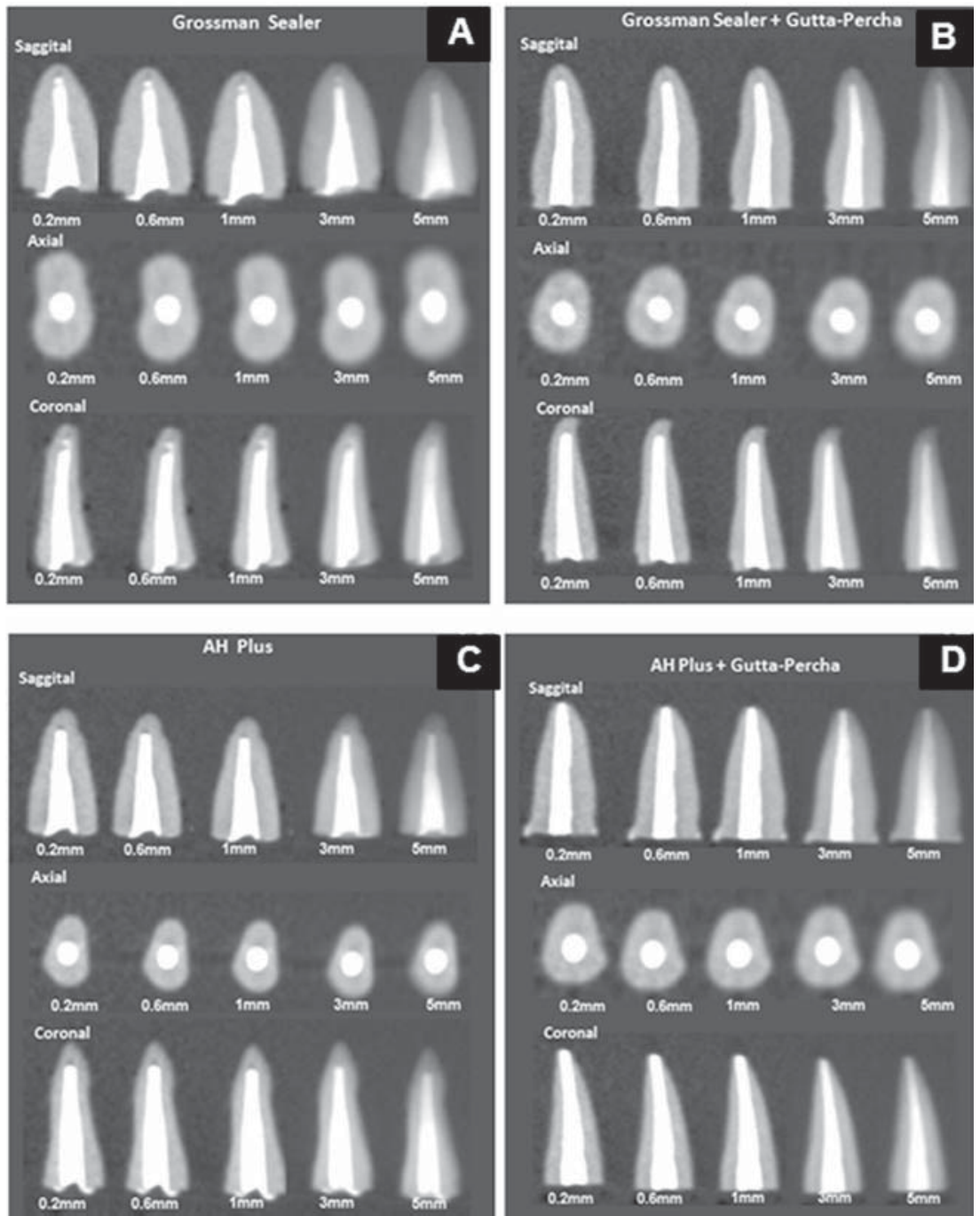

Figure 3- Cone-beam computed tomography images of root canal filling with Grossman Sealer (A), Grossman Sealer 26+gutta-percha (B), AH Plus (C), and AH Plus+gutta-percha (D) in different slice thickness and planes (sagittal, axial and coronal)

\section{decision.}

All measurements made on the СВCT images were acquired by two dental radiology specialists with the scanner's proprietary software (Xoran version 3.1.62; Xoran Technologies, Ann Arbor, MI, USA) in a PC workstation running Microsoft Windows XP professional SP-2 (Microsoft Corp, Redmond, WA, USA), with processor Intel ${ }^{\circledR}$ Core $^{T M} 2$ Duo-6300 $1.86 \mathrm{Ghz}$ (Intel Corporation, USA), NVIDIA GeForce 6200 turbo cache videocard (NVIDIA Corporation, USA) and Monitor EIZO - Flexscan S2000, resolution $1600 \times 1200$ pixels (EIZO NANAO Corporation Hakusan, Japan). All CBCT scans were reformatted using $0.2 \mathrm{~mm}, 0.6 \mathrm{~mm}, 1.0 \mathrm{~mm}, 3.0 \mathrm{~mm}$ and 5.0 $\mathrm{mm}$ slice thickness.

To determine the discrepancy between the RCF measurements made on the original root specimens and those made on the CBCT images, the same sites were evaluated on the CBCT scans using the same orientation (axial, sagittal and coronal). In all planes, measurements were made at $6.5 \mathrm{~mm}$ from the root apex. On axial images, the RCF measurement was made in the buccal/palatal direction; on sagittal images, in the mesial/distal direction; and on coronal images, in the buccal/ palatal direction.

One-way analysis of variance (ANOVA) and Tukey tests were used for statistical analyses. The significance level was set at $\alpha=5 \%$.

\section{RESULTS}

Results are shown in Tables 1 and 2. The variation of RCF dimensions on CBCT images ranged from $9 \%$ to $100 \%$ greater than those measured on the original root specimens. The lowest RCF dimensions (percentage values) corresponded to Sealer 26 and Sealer 26 plus gutta-percha points. Groups that were filled with sealers alone showed the greatest dimensional values in CВCT images when compared with groups filled with sealer and gutta-percha points, with statistically 
significant difference among the groups. When slice thicknesses varying from $0.2 \mathrm{~mm}$ to $5.0 \mathrm{~mm}$ were measured, an increase of $46.16 \%$ to $50.53 \%$ in RCF dimensions was noted, though without statistical significance. The different visualization planes analysis revealed an increase in RCF dimensions ranging from $35.48 \%$ (sagittal slice) to $59.28 \%$ (axial slice) (with statistically significant difference). Figures 2-3 illustrate the sagittal, axial and coronal views of the RCF using CBCT.

\section{DISCUSSION}

A new standard of contemporary endodontics has been created with the advent of CBCT $2,4-9,20,22,25,29$. For several years, RCF quality was evaluated in clinical practice according to a 2D image of 3D structures $^{4-8}$. The radiographic appearance of the filled root canal space is used to evaluate its sealing quality and to indicate the presence of apical periodontitis. However, the limitations of a radiographic assessment as a reference and study method have been demonstrated in several studies $^{6-9,20}$.

There is a possibility of interference from artifact caused by different densities from endodontic materials, which can cause errors of interpretation. Our main purpose was to determine the discrepancy of RCF measurements between original root specimens and СВCT images, and our findings showed that measurements obtained from CBCT images of RCF with sealers and sealers plus guttapercha were greater than those obtained on the original root specimens (Tables 1 and 2). These results bring important implications for the clinical evaluation of RCF and anatomic dental structures. Special attention should be paid depending on the density of the endodontic material and slice thickness/orientation which can lead to misdiagnosis.

CBCT measurement tools provide satisfactory information about linear distances within an anatomic volume $6-8,15,22,24,30$. Loubele, et al. ${ }^{21}$ (2008) compared the accuracy of CBCT and multislice CT for linear jaw bone measurements, and found that both methods were accurate when used to evaluate an ex vivo specimen. Mischkowski, et al. ${ }^{24}$ (2008) determined the geometric accuracy of CBCT scans in comparison with a multidetector computed tomography (MDCT) scanner. Their results showed that the CBCT devices provide satisfactory information about linear distances and volumes. MDCT scans proved slightly more accurate in both measurement categories, but this difference may be irrelevant for most clinical applications.

Recent studies using CBCT images detected voids in root filling ${ }^{1,13}$ and incomplete removal of filling material during endodontic retreatment.
Soğur, et al. ${ }^{30}$ (2007) showed that image quality of storage phosphor images was subjectively as good as conventional film images and superior to limited-volume СВСТ images for the evaluation of both homogeneity and length of root fillings in single-rooted teeth. Huybrechts, et al. ${ }^{13}$ (2009) analyzed voids in root fillings using intraoral analogue, intraoral digital and CBCT images. Voids larger than $30 \mu \mathrm{m}$ were detected by all imaging techniques. For small void detection, all digital intraoral techniques performed better than intraoral analogue and CBCT images.

The difference in density of RCF materials may have affected the results of several studies ${ }^{1,9,13,30}$, and was also found in our specimens. The endodontic sealers and gutta-percha used in our study have different physical and chemical properties because of different radiopaque substances (bismuth oxide, barium sulfate, zinc oxide). Estrela, et al. ${ }^{9}$ (2011) evaluated the effect caused by intracanal posts (glass-fiber post, carbon fiber root canal, prefabricated post-metal screws, silver alloy post and gold alloy post) on the dimensions of CBCT images of endodontically treated teeth. Gold alloy and silver alloy post dimensions were greater on CBCT scans than on the original root specimens.

$\mathrm{CBCT}$ reconstructions may show higher RCF dimensional values, as well as lack of image homogeneity and definition. Katsumata, et al. ${ }^{17}$ (2007) conducted an in vitro study about the effect of projection data discontinuity-related artifacts in limited-volume CBCT imaging of jaws. The effects of artifacts were scored as the difference in relative density between the lingual and buccal soft tissue. The intensity of artifacts increased when more objects were outside the area being imaged. Fewer artifacts were noted in images produced by the particular flat CBCT panel detector used in this investigation. Katsumata, et al. ${ }^{18}$ (2009) analyzed the relationship between density values and CBCT volume size using an Alphard CBCT system capable of providing different-size imaging volumes. The authors found that the data discontinuity-related effect was different in limited-volume CBCT scanning.

Considering that the higher density of RCF materials may produce image artifacts, special attention should be paid to the RCF evaluation of endodontically treated teeth. Any change from true dimension of RCT may favor false interpretation on real dentin remnants, and constitute potential risks of misdiagnosis. The implication of density artifacts on diagnostic procedures seems to be obvious ${ }^{28}$, and different correction methods have been investigated $3,10,12,16-19,27,28$. Azevedo, et al. ${ }^{3}$ (2008) studied the effect of incident radiation energy on the amount and extent of image artifacts over adjacent anatomic structures. The use of a harder 
energy beam during scanning appears to result in less extensive artifact formation.

A strong correlation between gray scale values on CBCT images and bone densities has been found by Haristoy, et al. ${ }^{10}$ (2008). This has implications for potential quantitative radiological approaches to determine bone density from CBCT images. However, given the variation of gray scale values despite normalization, it may be necessary to use calibration phantoms scanned simultaneously with the patient to ensure an accurate determination of bone density ${ }^{10}$. Hunter and McDavid ${ }^{12}$ (2009) showed that additional copper filtration suppresses beam hardening artifacts. In micro-computed tomography scanning based on bone mineral density measurements, the effects of beam hardening-induced cupping artifacts may be also minimized by beam filtration ${ }^{23}$.

CBCT provides a three-dimensional image, in which a new plane has been added: depth. Its clinical application results in greater accuracy and may be used in nearly all areas of dentistry: surgery, implants, dentistry, orthodontics, endodontics, periodontics, temporomandibular dysfunction, image diagnosis, and so on.

Few studies investigated the dimensional alterations of endodontic materials observed on CBCT images, and further studies should include other variables, such as the effect of artifacts on intracanal post alloys. The evolution of the new softwares certainly can reduce metallic artifact and dimensional alterations in future reconstructions of CBCT images. Periapical radiographs should be used as a reference standard, together with $С B C T$ image interpretation, when making endodontic diagnoses.

\section{CONCLUSIONS}

The results of this study showed that RCF dimensions were greater on CBCT images than on the original root specimens, especially when only sealer was used.

\section{REFERENCES}

1- Anbu R, Nandini S, Velmurugan N. Volumetric analysis of root fillings using spiral computed tomography: an in vitro study. Int Endod J. 2010;43:64-8.

2- Arai Y, Tammisalo E, Iwai K, Hashimoto K, Shinoda K. Development of a compact computed tomography apparatus for dental use. Dentomaxillofac Radiol. 1999;28:245-8.

3- Azevedo B, Lee R, Shintaku W, Noujeim M, Nummikoski P. Influence of the beam hardness on artifacts in cone-beam CT. Oral Surg Oral Med Oral Pathol Oral Radiol Endod. 2008;105:e48. 4- Bender IB. Factors influencing the radiographic appearance of bone lesions. J Endod. 1982;8:161-70.

5- Cotton TP, Geisler TM, Holden DT, Schwartz SA, Schindler WG. Endodontic applications of cone-beam volumetric tomography. J Endod. 2007;33:1121-32.
6- Estrela C, Bueno MR, Alencar AH, Mattar R, Valladares-Neto $\mathrm{J}$, Azevedo $\mathrm{BC}$, et al. Method to evaluate inflammatory root resorption by using cone beam computed tomography. J Endod. 2009;35:1491-7.

7- Estrela C, Bueno MR, Azevedo BC, Azevedo JR, Pécora JD. A new periapical index based on cone beam computed tomography. J Endod. 2008;34:1325-31.

8- Estrela C, Bueno MR, Leles CR, Azevedo B, Azevedo JR. Accuracy of cone beam computed tomography and panoramic and periapical radiography for detection of apical periodontitis. J Endod. 2008;34:273-9.

9- Estrela C, Bueno MR, Silva JA, Porto OCL, Leles CR, Azevedo BC. Effect of intracanal posts on dimensions of cone beam computed tomography images of endodontically treated teeth. Dental Press Endod. 2011;1:28-36.

10- Haristoy RA, Valiyaparambil JV, Mallya SM. Correlation of CBCT gray scale values with bone densities. Oral Surg Oral Med Oral Pathol Oral Radiol Endod. 2008;107:e28.

11- Hounsfield GN. Computerised transverse axial scanning (tomography). I. Description of system. Br J Radiol. 1973;46:101622.

12- Hunter A, McDavid D. Analyzing the beam hardening artifact in the Planmeca ProMax. Oral Surg Oral Med Oral Pathol Oral Radiol Endod. 2009;107:e28-e29.

13- Huybrechts B, Bud M, Bergmans L, Lambrechts P, Jacobs R. Void detection in root fillings using intraoral analogue, intraoral digital and cone beam CT images. Int Endod J. 2009;42:675-85. 14- Jian F, Hongnian L. Beam-hardening correction method based on original sonogram for X-CT. Nucl Instrum Methods Phys Res A. 2006;556:379-5.

15- Kamburoğlu K, Kiliç C, Ozen T, Yüksel SP. Measurements of mandibular canal region obtained by cone-beam computed tomography: a cadaveric study. Oral Surg Oral Med Oral Pathol Oral Radiol Endod. 2009;107:e34-42.

16- Katsumata A, Hirukawa A, Noujeim M, Okumura S, Naitoh M, Fujishita M, et al. Image artifact in dental cone-beam CT. Oral Surg Oral Med Oral Pathol Oral Radiol Endod. 2006;101:652-7. 17- Katsumata A, Hirukawa A, Okumura S, Naitoh M, Fujishita $M$, Ariji $E$, et al. Effects of image artifacts on gray-value density in limited-volume cone-beam computerized tomography. Oral Surg Oral Med Oral Pathol Oral Radiol Endod. 2007;104:829-36. 18- Katsumata A, Hirukawa A, Okumura S, Naitoh M, Fujishita M, Ariji $\mathrm{E}$, et al. Relationship between density variability and imaging volume size in cone-beam computerized tomography scanning of the maxillofacial region: an in vitro study. Oral Surg Oral Med Oral Pathol Oral Radiol Endod. 2009;107:420-5.

19- Ketcham A, Carlson WD. Acquisition, optimization and interpretation of $\mathrm{X}$-ray computed tomography imagery: applications to the geosciences. Comput Geosci. 2001;27:381400.

20- Lofthag-Hansen S, Hummonen S, Gröndahl K, Gröndahl H-G. Limited cone-beam CT and intraoral radiography for the diagnosis of periapical pathology. Oral Surg Oral Med Oral Pathol Oral Radiol Endod. 2007;103:114-9.

21- Loubele M, Van Assche N, Carpentier K, Maes F, Jacobs R, van Steenberghe $D$, et al. Comparative localized linear accuracy of small-field cone-beam CT and multislice CT for alveolar bone measurements. Oral Surg Oral Med Oral Pathol Oral Radiol Endod. 2008; 105:512-8.

22- Maret D, Molinier F, Braga J, Peters OA, Telmon N, Treil J, et al. Accuracy of 3D reconstructions based on cone beam computed tomography. J Dent Res. 2010;89:1465-9.

23- Meganck JA, Kozloff KM, Thornton MM, Broski SM, Goldstein $\mathrm{SA}$. Beam hardening artifacts in micro-computed tomography scanning can be reduced by X-ray beam filtration and the resulting images can be used to accurately measure BMD. Bone. 2009;45:1104-16. 
24- Mischkowski RA, Pulsfort R, Ritter L, Neugebauer J, Brochhagen HG, Keeve E, et al. Geometric accuracy of a newly developed cone-beam device for maxillofacial imaging. Oral Surg Oral Med Oral Pathol Oral Radiol Endod. 2007;104:551-9.

25- Mozzo P, Procacci C, Taccoci A, Martini PT, Andreis IA. A new volumetric CT machine for dental imaging based on the conebeam technique: preliminary results. Eur Radiol. 1998;8:1558-64. 26- Noujeim M, Prihoda TJ, Langlais R, Nummikoski P. Evaluation of high-resolution cone beam computed tomography in the detection of simulated interradicular bone lesions. Dentomaxillofac Radiol. 2009;38:156-62.

27- Ramakrishna K, Muralidhar K, Munshi P. Beam-hardening in simulated X-ray tomography. NDT\&E International. 2006;39:44957.
28- Rao SP, Alfidi RJ. The environmental density artifact: a beam-hardening effect in computed tomography. Radiology. $1981 ; 141: 223-7$.

29- Scarfe WC, Farman AG, Sukovic P. Clinical applications of cone-beam computed tomography in dental practice. J Can Dent Ass. $2007 ; 72: 75-80$.

30- Soğur E, Baksi BG, Gröndahl HG. Imaging of root canal fillings: a comparison of subjective image quality between limited conebeam $\mathrm{CT}$, storage phosphor and film radiography. Int Endod J. 2007;40:179-85. 